\title{
RESEARCH ON THE METHOD OF GIS-BASED ANALYSIS ON AGRICULTURAL REGIONAL COMPETITIVE INDUSTRIES
}

\author{
Kaimeng Sun, Yeping Zhu, Yanchao Xu \\ Chinese Academy of Agricultural Sciences Institute of Agricultural Information,Beijing \\ 100081 ,P. R. China
}

\begin{abstract}
The author introduces the main content of the research on the GIS-based regional agricultural analysis system of competitive industries, including the significance, the main contents and the implementation methods of the research, focusing on the classification of agricultural economic indicators for regional competitive industries, on the realization of regional choice based on GIS, and on the design of a computer system. The advantages of the regional agricultural industry from the analysis conduct a number of meaningful explorations on the ways and means, particularly making a number of new attempts on the use of GIS to analyze the agricultural regional competitive industries.
\end{abstract}

Keywords: GIS, Agricultural regional planning, System

\section{INTRODUCTION}

\subsection{Regional management of agriculture is necessary for the development of modern agriculture.}

Agricultural modernization includes the modernization of technology and management. Since China has a vast territory, there are many differences in climate, natural resources, endowments, and the people's living habits and agricultural development, which require a regulatory control measure to

Please use the following format when citing this chapter:

Sun, K., Zhu, Y. and Xu, Y., 2009, in IFIP International Federation for Information Processing, Volume 293, Computer and Computing Technologies in Agriculture II, Volume 1, eds. D. Li, Z. Chunjiang, (Boston: Springer), pp. 265-273. 
achieve inter-regional complementary and the relative balance of resources. So each area can form their own characteristics of the regional agricultural economy and prevent over-blind competition, which may lead to the waste of resources, caused by a sudden swing into action, without careful preparation, and the duplication of inter-regional input during the structural adjustment. Regional management can make the agricultural production of entire region become an organized workroom-style production workshop to provide high-quality, high efficiency and high-yield agricultural products.

\subsection{The concept of agricultural regional management}

Agricultural regional management includes social, economic, technical management. In social management, establishing a collaborative organization adjusting to social development trend is necessary. In the economic structure and development, following the restrictions of the natural conditions, the management is supposed to be market-oriented, to strengthen regional intergovernmental organization and interaction, to make the regional structures be complemented to each other according to local conditions, thus to establish a series of secondary and tertiary industries, to stimulate the growth of regional economy, and to optimize resource allocation and portfolio. In technology, we should establish a technology management system that adjusts the mechanisms for market transformation, reduce the cycle time of transforming agricultural technology into productivity, and improve the motivation and ability of technological innovation. Agricultural regional management is the general idea of agricultural development. The development of agriculture should be based on the perspective of the overall situation and pay attention to forwardlooking, regional, and actively implement the adjustment of industrial structure, raise the level of agricultural operations. The implementation of unified guidance and management can make the quality of agricultural products achieve a achieve uniform standard, effectively control the quality of agricultural products amounted to less than the state safety standards caused by technical problems, and can also promote the development of market and withstand market risks together.

\subsection{Issues to be solved in our research}

According to the regional spatial distribution of major agricultural industry, agricultural resources and economic data, we can establish countybased regional advantages industry evaluation indicators, in which the characteristics of region's main agricultural industry are supposed to match the environmental parameters of natural resources; study the advantage index and the methods of evaluating the comprehensive competitiveness of 
regional competitive industries; design and develop a regional agricultural analysis system of competitive industries based on the evaluation indicators and evaluation methods. According to the basic data, the system can analyze and evaluate the regional advantages and characteristics, to provide a scientific basis for the determination of regional competitive industries and the rational adjustment of industrial structure in the region, thus achieving the implementation of agricultural regional management.

\section{RESEARCH METHODS}

\subsection{Design evaluation indicators}

According to conventional agricultural regional evaluation methods, evaluation indicators usually include the following aspects:

\subsubsection{Natural resources}

Natural resources impacting on regional agricultural production mainly include the following three aspects: land resources, climate and water resources.

\section{A. Land resources}

Being the sites for human's life and production, land resources are the most basic means of production for agricultural production and planting industry. In planting production, land resources not only affect the status of crop production, but also restrict the production structure of planting industry. The characteristics of them include quantity limitation, fixed location and quality differences. The total land resources are limited and subject to the constraints of nature. They occupy a fixed position after forming, which needs a very long time and corresponding conditions, so that people can not move them in space.

In our system, the indicators referring to land resources are followings: area of arable land, area of harvest guaranteed whether drought or floods, and so on.

\section{B. Climate resources}

Climate resources are the comprehensive long-term performance of all kinds of weather elements, including light, heat, water, wind and atmospheric composition. They are the main natural resources which are indispensable to planting production. Under certain technical and economic conditions, they can provide material and energy for human beings. They are 
the key factors that constrain and affect agricultural production and its distribution. The characteristics of them include the heterogeneity of the region, the difference in time and the renewability.

\section{Water resources}

Water resources are the most active environmental factors. Natural reserves of water are diverse, and they generally refer to the surface water and groundwater formed by precipitation. They have a great impact on the production of various regions' planting industry, and supposed to be an important condition for the growth of crops. The characteristics of them include the regional scarcity of quality and quantity, functional irreplaceability and renewability.

In our system, the indicators referring to water resources are followings: irrigated area, and so on.

\subsubsection{Social resources}

\section{A. Labor resources}

Labor resources refer to the sum of the ability to work within the scope of an overall population, also called human resources. Labor is the fundamental element of the national economy, constituting the basic prerequisite for socio-economic operation, promoting the development of material resources, and actively adapting to material resources. It is a major production factor in crop production, the richness of its resources directly affects the situation of crop production comparative advantage.

Its characteristics include subjective initiative, the restriction of time, the difference in quality, creativity and renewability.

In the system, the indicators referring to labor resources are followings: rural labor, staff number, and so on.

\section{B. Funds}

Funds refer to the value contented in the process of production and circulation process, keeping constant moving and being value-added. Being a means, funds are used by workers to increase the social wealth and social value. They are supposed to be a tool to carry out the socialist economic construction and constantly improve people's living standard. The number of capital input to agricultural production directly affects the level of production efficiency. The characteristics include homogeneity, mobility and value-added.

In the system, the indicators referring to funds are followings: total income, agricultural income, industrial revenue, livestock income, service income, planting income, forestry income, fisheries earnings and so on.

\section{Technology}

The development of production is closely linked to scientific and technological development. Being the primary means to improve labor 
productivity, science and technology is an important factor of promoting regional economic development. The improvement of agricultural production technology can greatly improve the efficiency of agricultural production; increase the level of crop production advantages and their income. Its technical features include that it can be commercialized, developed, dedicated, and promoted sharing.

In the system, the indicators referring to technology are followings: permu yield of all kinds of food crops, per-mu yield of cash crops, and so on.

\subsubsection{The classification of indicators in the system}

Based on the above indicators, we will divide the indicators of the system into followings according the analysis and the needs of evaluation:

A. resource data: including land, water, staff and so on;

B. production of food crops: mainly including gross food yield and per$\mathrm{mu}$ yield of the main food crops (such as wheat, corn, rice, etc.);

C. production of economic crops: per-mu yield of major economic crops (such as cotton, oil-bearing crops, hemp, sugar, etc.);

D. aquaculture industry: including aquaculture industry of fishes and poultry livestock;

E. township enterprises: the number of township enterprises, the number of the staff, the number of total income, profits and taxes, and so on;

F. major economic indicators: total income, the ratio of agricultural income, the ratio of industrial income, the ratio of livestock income, the ratio of planting income to the agricultural income, the ratio of forestry to the agricultural income.

\subsection{GIS spatial database related to agricultural economy database}

Based on the GIS development tools named SuperMap, using the county digital map and its spatial database, using the county code for the key, the spatial database is linked to the agricultural economy database. Although increased the workload of the design process, this approach has the following advantages:

a. The properties of the original spatial database are not changed and the import volume of the agricultural economic data is reduced;

b. The integrity of the agricultural economy database can be ensured, and it will provide the future security of data with convenience. 


\subsection{Calculation of regional evaluation indicators}

\subsubsection{Identify the region and neighboring ones based on GIS technology}

During the analysis, determine the region and the neighboring comparative ones is supposed to be the first step. The region to be analyzed takes county as a unit, and the region used as the contrast can be the neighboring ones.

\section{A. Regional choice}

There are two ways to choose the region:

\section{a. Choose the region according to its name}

According to the name of the county to be analyzed, select the province which the county belongs to at first, and then the county. After the name of the county been chosen and determined, the identified region will be highlight on the county map by the system according the chosen name. The following is the process: Select province name $->$ Select county name $->$ Enter the spatial database and search the county name $\rightarrow$ Highlight the search results on the map $->$ Get agricultural economic data of the corresponding region.

b. Choose the region on the map directly

According to the map of the county displayed in the system, click on the map to choose the region directly, and the region will be highlighted.

B. The choice of the (neighboring) region used as the contrast

The selection of adjacent area is based on GIS spatial analysis functions, choosing the neighboring regions of the selected area as the region's contrast, and getting agricultural economic data of these regions from the corresponding database, to prepare for calculation.

\subsubsection{Calculation using comparative advantages of regional agricultural industry}

According to the indicator system, the comparative advantage calculation is based on several aspects, such as the resource data, the production of food crops, cash crops production, aquaculture, township enterprises and major economic indicators, and so on. Calculated as follows:

\section{A. Calculate the ranking of the indicators}

According to the overall number of the selected regions and comparative regions, and the design of the indicator system under the project, calculate the regional rankings of various economic indicators, including the 5 indicators of agricultural resources; the 8 calculation indicators of food crops production, such as the per-mu yield of various types of food crops and so on; 
the 7 calculation indicators of economic crop production; the 4 indicators of planting industry, the 5 indicators of township enterprises; and the 9 major economic indicators.

Based on the results of the above calculation, the strengths and weaknesses of the production and economic indicators in the selected regions and comparative ones can be found, and thus largely determine the region's situation of agricultural competitive industries.

\section{B. Calculating the overall situation of the evaluation}

Based on the above six categories of indicators, according to the rating of "A, B, C, D, E", calculate the overall level of selected regions in terms of regional comparison. The followings are the process of calculation: the numerical sum of regional rankings divided by the number of regions, and the results then divided by 5 . The smallest number will be ranked as "A", etc. From the orders, one can see category ranks of the selected areas and comparative regions, then the overall situation of the selected area compared to the comparative regions.

\subsubsection{The expression of the results of the overall evaluation and calculation}

\section{A. Graphical expression}

The results of calculation can be shown in the form of histograms, according to the classification of the indicators. So users can directly see the situation of the indicators of the selected regions and comparative regions.

\section{B. Text expression}

The results of the calculated rankings of the indicators and the overall evaluation results of category indicators will be described and displayed in the form of text.

The primary process of the system is shown in Figure 1:

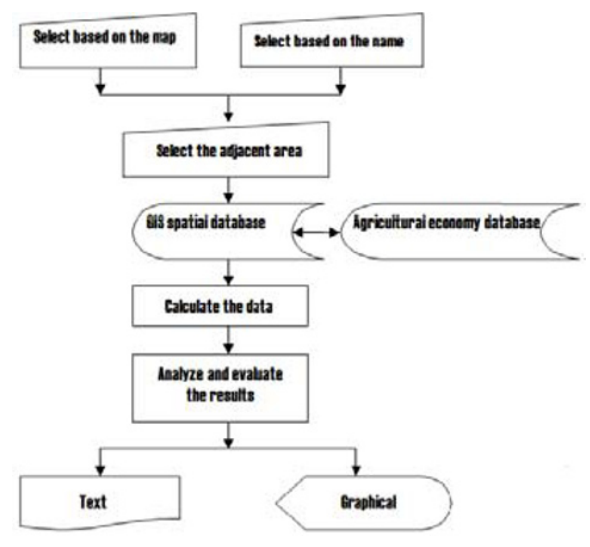




\section{FUNCTIONAL DIVISION OF THE SYSTEM}

\subsection{Data management module}

It is composed of GIS spatial database management and agricultural economy database management, including data importing, data editing, data maintenance, and so on.

\subsection{Statistical calculation module}

According to the requirements of functional design, complete the basic data extraction and simple calculation, for example, calculated per-mu yield based on the sown area of wheat and its gross yield; according to the data of the selected regions and comparative regions and the results of calculation, sort the results, and so on.

\subsection{Analysis and evaluation module}

According to the results and their sort, in accordance with the classification of agricultural economic data, provide the comprehensive evaluation of the region in the agricultural industries and economic indicators.

\subsection{Input and output module}

It includes the interaction of user-related part, such as: map, the choice of regional data, the graphics of calculated, analyzed and evaluated results, the screen display of text expression and print output, and so on.

\section{CONCLUDING REMARKS}

As the great differences in natural resources, social resources, economic infrastructure, technical conditions and other aspects between regions, the comparative advantages of our country's crop production have a big difference. First of all, the comprehensive comparative advantages of the crop production in different regions have differences. Some areas have crops with comprehensive comparative advantage, which may be in a relatively disadvantageous position in other regions. The crops with a relatively disadvantageous position in some areas of crops may have relatively comprehensive advantages in other regions. Secondly, the overall production 
in agriculture has different strengths. In some areas, planting industry as a whole may have strong comparative advantages and in some other areas, planting industry may be weak as a whole. In the process of the crop structure adjustment, not only give full play to the comprehensive comparative advantages of all kinds of crops in the region, we should also take full advantage of the planting industry as a whole in comparative advantages, not only expand the crop production with comprehensive comparative advantages, and reduce the one with comparing disadvantages, but also take full consideration for the comparative advantages of planting industry at the same time, then planting industry will be done to improve efficiency, and the income of farmers will be increased.

The analysis on agricultural regional competitive industries proposed in the paper, has integrated the natural, social, economic and many other factors, made certain sense to the regional crop structure adjustment. However, the regional industrial structure adjustment is a complicated systematic project. The results of this study can not simply be a relatively perfect solution to the problem. We are also trying to conduct much deeper study ranged from the contents of indicators to the methods of analysis, there are many issues worthy of further exploration and study.

\section{ACKNOWLEDGEMENT}

This research was supported by National Scientific and Technical Supporting Programs Funded by Ministry of Science and Technology of China(2006BAD10A06,2006BAD10A12), Special Fund of Basic Scientific Research and Operation Foundation for Commonweal Scientific Research Institutes(2008J-1-06)

\section{REFERENCES}

A. Wang Jiazheng, Xiang Anqiang, Preliminary exploration of agricultural regional management, Ancient and Modern Agriculture, 2005 (4), 1-4;

B. Zhu Liqun,Bian Xinmin,Guo Junyang, Research on regional crops, planting comparison model, China's Agricultural Resources and Division", 2005 (10), 26 Vol 5, 9-13; 